\title{
An Intelligent, Affective and Configurable Tutor for 3rd Grade Natural Numbers Teaching
}

\author{
María Lucía Barrón-Estrada, Ramón Zatarain-Cabada, Margarita Aranda-Ortega, \\ H.E. Gómez-Pérez, and José Mejía-Arredondo \\ Instituto Tecnológico de Culiacán, Sinaloa, M exico \\ \{lbarron, rzatarain, maranda, hgomez, jmejia\}@itculiacan.edu.mx
}

\begin{abstract}
The current document presents the design and implementation of an Intelligent Tutoring System (ITS) capable of being configured by different experts, in fields that are important for an ITS. Several features have been implemented so that the specialists are the ones who provide the required tools for the teaching of $3^{\text {rd }}$ grade natural numbers. The ITS can be modified by adding fuzzy sets and rules, by changing the Affective module, the diagnostic test and student's learning style. This allows the ITS to change according to the environment and to the needs of the students that uses it.
\end{abstract}

Keywords: Affective computing, intelligent tutoring systems, neural nets, fuzzy systems.

\section{Introduction}

The study of human emotion has become increasingly important in different fields, due to the impact they got in our activities performance $[1,2]$. In the past couple of years the intelligent tutorial systems (ITSs) have incorporated the ability to recognize the affective state of students, which has led to a change on the way they interact taking this in consideration [3-7]. Many of the work so far is being done with the use of special sensors like posture chairs or conductive bracelets [8], but they produce an intrusive and annoying sensation to users. This problemhas been solved by some approximations that include the emotion detection inside the ITS [9].

This paper presents a way to achieve an integration of different aspects like affective state, learning style and the level of knowledge of natural numbers the students have. This is accomplished with the use of a Kohonen neural net on a dedicated server out of the ITS environment to recognize the emotions, fuzzy sets and rules to detect de current student level, taking as input the exercises answers and finally an specialized test for the learning style recognition [10].

An ITS is as smart as the knowledge introduced by experts, that's why implementing a platform that is capable of being used by multiple specialists, will gain the necessary experience equal or superior to any other ITS out there. We made a comparis on between different ITS [11-13] which are considered the best on their respective fields. 
María Lucía Barrón Estrada, Ramon Zatarain Cabada, Margarita Aranda-Ortega, et al.

The article is divided as follows: Section 2, Configuring the ITS, explain the capability of configuration by different experts, providing a fundamental feature of customization that makes the ITS capable of being used on different environments. Section 3, ITS Domain, describe the subset of lessons considered from the 3rd grade math book [14]. Section 4, ITS Architecture, shows the structure and relation of the most important components, focusing on those that handle the artificial intelligence. Section 5, Tests and evaluation of the ITS, Considers different aspects selected to make the comparis on with multiple ITSs. The last part of the paper is Section 6, Conclusions, which shows the final results of the investigation.

\section{Configuration of the ITS}

The most distinguish feature of the ITS is the capability of external configuration by an expert in a specific domain. In the exercises case, the teacher is able to introduce the lessons he considers are the best for his students. The same applies for the neuro-fuzzy component, in which a computational expert can access an API to input the rules and sets, in a way such that, when the student makes a mistake or scores an answer, the ITS determines the classification of the student's knowledge. In the same way, the learning style test can be swapped by a psychologist to determine the best learning procedure the student needs and improve the information the ITS have. This leads to a direct improvement in the understanding of the lessons.

The ITS use an affective component to process images collected while the student is answering exercises. This extendable API was conceived with the sole purpose of providing a tool to interexchange the emotion recognition, in a way that the ITS is not directly affected, and the user can't notice. All this capabilities of configuration are implemented in the JSON format, which is defined as a standard of information transfer on the web. The structure it carries can be generated by any online tool, making it easily accessible for experts.

\section{ITS Domain}

The free text book provided by the Secretary of Public Education (SEP) in México, "Matemáticas 3er Grado", contains 17 subjects. For the design of the ITS, the domain of Natural Numbers was selected. The book has spread the topic across several blocks. Each block contains different lessons that define the objectives the student should meet to perform well in an evaluation.

\section{$4 \quad$ ITS Architecture}

The ITS has a relaxed layered architecture which can be visualized in Figure 1. Functions on each layer are explained below. 


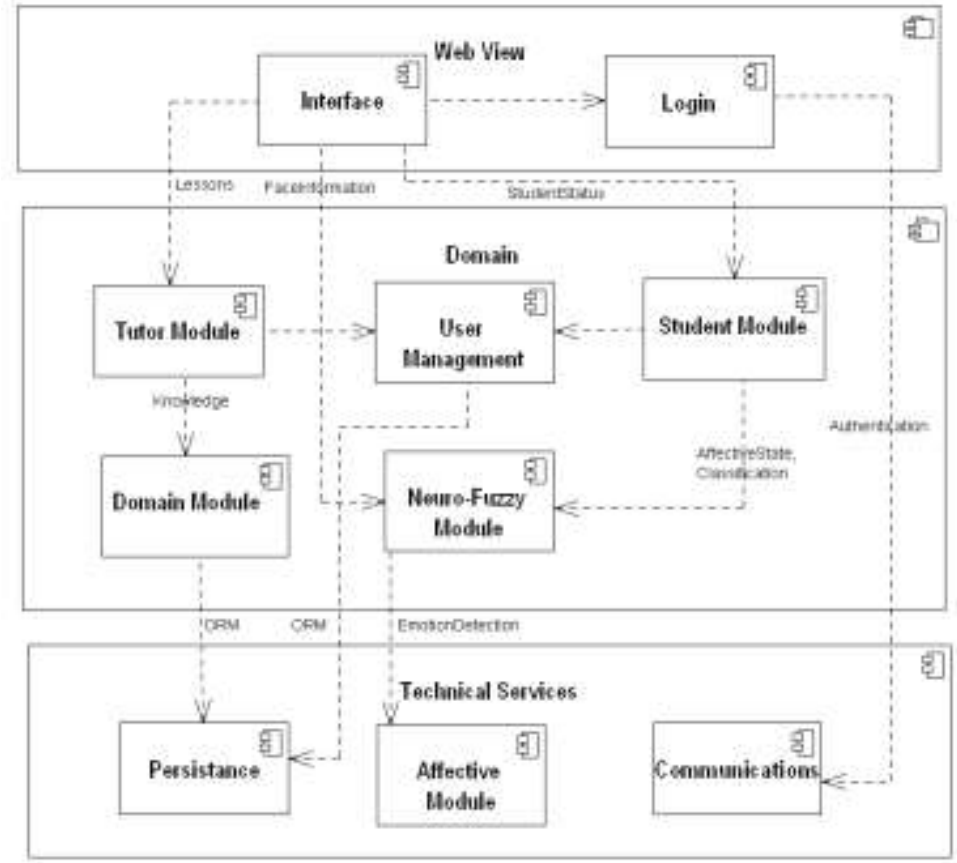

Figure 1. ITS Architecture.

\subsection{Web View Layer}

It is used for the presentation of the tutor and userinteraction. It has two components: Interface: It is what the user visualizes and it's implemented with HTML5, CSS3 and JavaScript. Login: It provides communication to enter the tutor via Facebook, but plans are in motion to increase it to google+ and twitter via "OAuth authentication".

\subsection{Domain Layer}

The domain layer implements everything about the tutor logic, artificial intelligence and information transfer to database; all in this layer is implemented in PHP and consists of five components.

\subsection{Tutor Module}

This module encodes teaching methods that are appropriate for the study area and the student. Based on data of the student's strengths and weaknesses, level of knowledge, and learning style, the tutor selects the most appropriate educational intervention. For example, if a student has been assessed as a beginner in any given lesson, the module shows some examples of the procedure step by step before inviting the user to answer. 
María Lucía Barrón Estrada, Ramon Zatarain Cabada, Margarita Aranda-Ortega, et al.

It can also provide feedback, explanations and training as the participant performs the process. As the student gains experience, the module may decide to bring increasingly complex scenarios.

Domain Module. It contains a computational representation of an expert in the field of Natural Numbers. This knowledge allows the ITS to compare the student's actions with that of an expert, to calculate what the student knows and needs to learn. A variety of AI techniques are used to capture how a problem can be solved. For example, rules are used to allow the ITS to generate problems on the fly. It also allows the developer to create templates, which specify an allowable sequence of correct actions. This method avoids the encoding of all possible problems the student can have, and it only requires the specification of how the student need to respond in a scenario.

Student Module. It evaluates the performance of each student to determine their knowledge, skills and reasoning skills. By keeping a module with the details of the strengths and weaknesses of the students, the ITS can offer very specific, relevant instruction.

Learning styles. To determine the learning styles of the students, the Felder-Silverman test [15] is used. This test consists of 44 questions and it is performed at the start. The student's learning style is stored on his academic profile and with this information the ITS selects appropriate material for the lessons, so that the student can learn according to their learning style. In this research only verbal and visual style are considered.

User management. It is the component that accesses the service layer to perform the information saving. It is implemented so that everything is totally encapsulated, in a simple and fast way.

Neuro-fuzzy module. It contains the necessary classes for the fuzzy logic and the connection to the affective component, to provide the information necessary for the ITS to make the right decisions.

Fuzzy logic. The ITS uses the theory of fuzzy sets and rules to calculate the vague and ambiguous values of fuzzy variables time, emotion and exercise difficulty. The result of this calculation will be taken into account for the next exercise that will be presented to the student.

A fuzzy set can be defined simply as a set with fuzzy boundaries [16].Viewed in another way, in the fuzzy theory, a fuzzy set A of universe $\mathrm{X}$ is defined by the function $\mu_{A}(x)$ called the membership function of the A set. The following equation defines this:

where:

$$
\mu_{A}(x): X \rightarrow[0,1]
$$

$$
\begin{aligned}
& \mu_{A}(x)=1 \text { If } x \text { is totally in } A ; \\
& \mu_{A}(x)=0 \text { If } x \text { is not in } A ; \\
& 0<\mu_{A}(x)<1 \text { if } x \text { is partially in } A ;
\end{aligned}
$$

Some fuzzy rules that are used in our system are: 
1. If (knowledge is low) and (time is slow) and (emotion is engaged) then (execiseDifficulty is low).

2. If (knowledge is regular) and (time is fast) and (emotion is distracted) then (exerciseDifficulty is high).

3. If (knowledge is regular) and (time is slow) and (emotion is neutral) then (exerciseDifficulty is low).

4. If (knowledge is regular) and (time is regular) and (emotion is engaged) then (exerciseDifficulty is high).

5. If (knowledge is good) and (time is fast) and (emotion is engaged) then (exerciseDifficulty is high).

\subsection{Services Layer}

It contains all the low-level services communication, such as database, connection between systems and interface to the affective module. This layer has three components described below.

Persistence. Handles everything related to database. This component provides the interfaces needed to save and uses ORM technology to be able to persist on different database suppliers.

Affective Module. Responsible for image processing and the return of the emotion that was detected to the upper layer. It provides an API for easy access.

Communications. It is used for interaction with other systems, such as the login to Facebook

\section{Proof and Evaluation of the ITS}

The ITS has not yet been tested with students because until this point we are ending the integration of the modules that conforms it. Alternatively, it was decided to benchmark with other intelligent tutoring systems that have a similar purpose. The diverse characteristics of ITS are listed and an assessment is proposed using a Likert scale with values 5-1 representing strongly agree to strongly disagree res pectively. This evaluation can be seen on Table 1 .

\section{Conclusions}

During development, it was sought to implement all the features that requires a good ITS, these were: emotional recognition, learning styles, reaction to the cognitive needs of the configuration by experts. The proposed features were evaluated against implemented features and it was concluded that the potential of an ITS to handle the latest on configuration technology has greater influence in the education sector, since it can be adapted to a wider number of environments, such as Mexico. 
María Lucía Barrón Estrada, Ramon Zatarain Cabada, Margarita Aranda-Ortega, et al.

Table 1. Evaluation of the ITS against others with similar purpose.

\begin{tabular}{|c|c|c|c|c|c|}
\hline $\begin{array}{c}\text { ITS } \\
\text { Characteristics }\end{array}$ & $\begin{array}{c}\text { Characteristic } \\
\text { description }\end{array}$ & CTAT & $\begin{array}{l}\text { Animal } \\
\text { Watch }\end{array}$ & $\begin{array}{l}\text { Active } \\
\text { Math }\end{array}$ & $\begin{array}{l}\text { Config- } \\
\text { urable } \\
\text { ITS }\end{array}$ \\
\hline Generativity & $\begin{array}{l}\text { The ability to generate } \\
\text { appropriate problems, } \\
\text { hints, and help } \\
\text { customized to student } \\
\text { learning needs }\end{array}$ & 3 & 5 & 4 & 5 \\
\hline $\begin{array}{l}\text { Student } \\
\text { modeling }\end{array}$ & $\begin{array}{l}\text { The ability to represent } \\
\text { and reason about a } \\
\text { student's current } \\
\text { knowledge and } \\
\text { learning needs and to } \\
\text { respond by providing } \\
\text { instruction }\end{array}$ & 3 & 5 & 4 & 5 \\
\hline Expert modeling & $\begin{array}{l}\text { A representation and } \\
\text { way to reason about } \\
\text { expert performance in } \\
\text { the domain and the } \\
\text { implied capability to } \\
\text { respond by providing } \\
\text { instruction. }\end{array}$ & 5 & 5 & 3 & 5 \\
\hline Mixed initiative & $\begin{array}{l}\text { The ability to initiate } \\
\text { interactions with a } \\
\text { student as well as to } \\
\text { interpret and respond } \\
\text { usefully to student- } \\
\text { initiated interactions. }\end{array}$ & 5 & 3 & 4 & 2 \\
\hline $\begin{array}{l}\text { Interactive } \\
\text { learning }\end{array}$ & $\begin{array}{l}\text { Learning activities that } \\
\text { require authentic } \\
\text { student engagement } \\
\text { and are appropriately } \\
\text { contextualized and } \\
\text { domain-relevant. }\end{array}$ & 5 & 4 & 4 & 4 \\
\hline $\begin{array}{l}\text { Instructional } \\
\text { model }\end{array}$ & $\begin{array}{l}\text { The ability to change } \\
\text { teaching mode based on } \\
\text { inferences about a } \\
\text { student's learning. }\end{array}$ & 4 & 4 & 4 & 4 \\
\hline Self-improving & $\begin{array}{l}\text { A system's ability to } \\
\text { monitor, evaluates, and } \\
\text { improves its own } \\
\text { teaching performance } \\
\text { based on its experience } \\
\text { with previous students. }\end{array}$ & 3 & 3 & 3 & 3 \\
\hline
\end{tabular}


Another valuable contribution to the project was the implementation of access through social networks, which are used every day by a large number of students; this opens a great niche for participation.

Future work seeks to implement a greater number of learning styles to lessons, add other ways to recognize the cognitive state of the student so that not only experts in fuzzy logic can modify it and improvements to the pedagogical agent, so that it'll be able to respond to voice input by the student.

\section{References}

1. Ekman, P.: Are there basic emotions? Psychological Review, 99, pp. 550-553 (1992)

2. Mandler, G.: Emotion. In: B. M. Bly \& D. E. Rumelhart (Eds.), Cognitive science. Handbook of perception and cognition, 2nd ed., pp. 367-384. Academic Press (1999)

3. Aleven, V., Koedinger, K.: An effective metacognitive strategy: learning by doing and explaining with a computer-based cognitive tutor. Cognitive Science, 26(2), pp. 147-179 (2002)

4. Anderson, R., Boyle, C. F., Corbett, A. T., Lewis, M. W.: Cognitive modeling and intelligent tutoring. Artificial Intelligence, 42, pp. 17-49 (1990)

5. Carbonell, J. R.: AI in CAI: An artificial intelligence approach to computer-aidedinstruction. IEEE Transactions on Man-Machine System, MMS, 11(4), pp. 190-202 (1970)

6. Clancey, W. J.: Transfer of rule-based expertise through a tutorial dialogue. Ph.D. thesis, Department of Computer Science, Stanford University (1979)

7. Woolf, B. P.: Building intelligent interactive tutors. Morgan Kaufmann (2009)

8. Arroyo, I., Woolf, B., Cooper, D., Burleson, W., Muldner, K., Christopherson, R.: Emotions sensors go to school. In: Proceedings of the 14th international conference on artificial intelligence in education (AIED 2009), Brighton, UK, pp. 17-24. IOS press, Amsterdam (2009)

9. Zatarain-Cabada, R., Barrón-Estrada, M.L., Beltrán, J.A., Cibrian, F.L., Reyes-García, C., Hernández, Y.: Fermat: merging affective tutoring systems with learning social networks. In: Proceedings of the 12th IEEE international conference on advanced learning technologies, Rome, Italy, pp. 337-339. IEEE Computer Society (2012)

10. Felder, R. M., Solomon, B. A.: Index of Learning Styles Questionnaire (1991)

11. Beal, C.R., Arroyo, I., Cohen, P.R., Woolf, B.P., Beal, C.R. Evaluation of AnimalWatch: An intelligent tutoring system for arithmetic and fractions. Journal of Interactive Online Learning, 9 (1), pp. 64-77 (2010)

12. Aleven, V., McLaren, B. M., Sewall, J., Koedinger, K. R.: The cognitive tutor authoring tools (CTAT): Preliminary evaluation of efficiency gains. In: Intelligent Tutoring Systems, pp. 61-70, Springer Berlin Heidelberg (2006)

13. Melis, E., Siekmann, J.: Activemath: An intelligent tutoring system for mathematics. In: Artificial Intelligence and Soft Computing-ICAISC 2004, pp. 91-101. Springer Berlin Heidelberg (2004)

14. Secretaria de Educación Pública: Matemáticas Tercer Grado. México. Chanti Editores (2012)

15. Felder, R. M., Silverman, L.K.: Learning and teaching styles in engineering education. Engineering Education, vol. 78, pp. 674-681 (1988)

16. Negnevitsky, M.: Artificial Intelligence a guide to intelligent systems. Pearson Education (2005) 